\title{
Enhanced mucosal re-epithelialization induced by short chain fatty acids in experimental colitis
}

\section{J.E. Aguilar-N ascimento L.R. França-da-Silva A.F. de-Oliveira and M.H. Gomes-da-Silva}

\author{
Departamento de Cirurgia, Hospital U niversitário Julio M üller, \\ Universidade Federal de Mato Grosso, Cuiabá, MT, Brasil
}

\section{Correspondence \\ J.E. Aguilar-N ascimento \\ Departamento de Cirurgia \\ Hospital U niversitário Julio M üller \\ R. Estevão de Mendonça, 81 \\ apto 801 \\ 78045-200 Cuiabá, MT \\ Brasil \\ Fax: + 55-65-624-7149 \\ E-mail: aguilar@ nutecnet.com.br}

Research supported in part by CNPq.

Received September 11, 1998 Accepted May 24, 1999

\section{Abstract}

The short chain fatty acids (SCFA) are the best nutrients for the colonocytes. Glucose is poorly used as a fuel but may be transformed into SCFA by colonic bacteria. The aim of this study was to investigate the effect of SCFA or glucose on experimental colitis. Colitis was induced in $30 \mathrm{Wistar}$ rats by colonic instillation of $4 \%$ acetic acid. Five days later they were randomized to receive twice a day colonic lavage containing saline (controls, $\mathrm{N}=10), 10 \%$ hypertonic glucose $(\mathrm{N}=10)$ or SCFA $(\mathrm{N}=10)$ until day 8 when they were killed. At autopsy, the colon was removed and weighed and the mucosa was evaluated macro- and microscopically and stripped out for DNA assay. Data are reported as mean $\pm \mathrm{SD}$ or median [range] as appropriate. All animals lost weight but there was no difference between groups. Colon weight was significantly lower in the SCFA group $(3.8 \pm 0.5 \mathrm{~g})$ than in the control $(5.3 \pm 2.1 \mathrm{~g})$ and glucose $(5.2 \pm 1.3 \mathrm{~g})$ groups $(\mathrm{P}<0.05)$. Macroscopically, the severity of inflammation was less in SCFA (grade 2 [1-5]) than in control (grade 9 [4-10]) and glucose-treated (grade 9 [2-10]) animals $(\mathrm{P}<0.01)$. Microscopically, ulceration of the mucosa was more severe in the glucose and control groups than in the SCFA group. The DNA content of the mucosa of SCFA-treated animals $(8.2$ [5.0-20.2] $\mathrm{mg} / \mathrm{g}$ of tissue) was higher than in glucosetreated $(5.1[4.2-8.5] \mathrm{mg} / \mathrm{g}$ of tissue; $\mathrm{P}<0.01)$ and control $(6.2$ [4.5$8.9] \mathrm{mg} / \mathrm{g}$ of tissue; $\mathrm{P}<0.05)$ animals. We conclude that SCFA may enhance mucosal re-epithelialization in experimental colitis, whereas hypertonic glucose is of no benefit.

\section{Introduction}

The treatment of non-complicated ulcerative colitis is aimed at reducing the inflammatory reaction and healing the colonic epithelium. In the clinical setting, corticosteroids, 5-aminosalicylic acid compounds and immunosuppressants are the drugs most frequently used (1).

In patients with ulcerative colitis, the fe-

\section{Key words}

- Short chain fatty acids

- Ulcerative colitis

- Glucose

- Colon

- Inflammation

- Mucosa cal concentration of short chain fatty acids (SCFA) seems to be diminished and apparently the oxidation of these nutrients is impaired by the colonic mucosa cells $(2,3)$. SCFA are the best nutrients for the colonocytes and provide up to $70 \%$ of the energy supply to the mucosa (3). Butyrate, propionate and acetate, the most important SCFA, have a direct trophic action on the colonic mucosa. They are products of the fermenta- 
tion of fibers and other polysaccharides by colonic anaerobic bacteria $(4,5)$. Glucose is used poorly as a fuel by the colonic mucosa. However, it could be a suitable substrate to be transformed into SCFA by bacterial metabolism if it were to reach the colon in appreciable quantities (5). Kinetic studies on the metabolism of SCFA and glucose in isolated human colonocytes have shown that butyrate is an energy source for the colonic mucosa both in cells derived from healthy individuals and in those obtained from patients with colitis (6). Thus, colonic lavage with nutritional solutions, while providing energy, could help reverse the local conditions that militate against the regeneration and healing of the mucosa in ulcerative colitis. By intensifying crypt cell proliferation, nutritional solutions could facilitate epithelialization and quickly fill the ulcers in colitis. SCFA may also stimulate the colonic blood flow and uptake of oxygen, which is especially important for healing (7). In fact, colonic lavage with SCFA solutions seems to improve the inflammation of the mucosa in diversion (8) or ulcerative colitis (9) patients.

However, the effect of nutritional solutions on experimental colitis has not been thoroughly studied (10). Previous studies have focused on the reduced inflammatory response induced by butyrate enemas in colitic rats by measuring the transglutaminase (11) or the myeloperoxidase activities (12). Thus, an investigation of the response of the colitic mucosa to other nutrients could be of some importance in the understanding and management of these cases. The aim of the present study was to investigate the influence of nutritional solutions containing SCFA or hypertonic glucose on the colitic mucosa in an experimental rat model.

\section{Material and Methods}

Thirty male Wistar rats (350-380 g) were kept in the laboratory environment for three days on a 12-h light/12-h dark cycle before the study. The animals received standard rat chow containing $32 \mathrm{~g}$ of nitrogen $/ \mathrm{kg}$ and $9 \%$ fiber (Ralston Purina, São Paulo, SP, Brazil; basic composition: corn, wheat, soybean, meat, raw rice, vitamins and minerals) and drank water ad libitum throughout the study.

\section{Induction of colitis}

After a 12-h fast, the animals were lightly sedated with inhalatory ether. An 8-Fr plastic catheter was lubricated with jelly and inserted $10 \mathrm{~cm}$ up into the colon through the anal canal. A previous pilot study had shown that by this technique the tip of the catheter would lie at or near the splenic flexure of the colon. With the animal placed in the Trendelemburg position, $2 \mathrm{ml}$ of a solution containing $4 \%$ acetic acid was instilled into the colonic lumen through the catheter connected to a syringe. After instillation the rats were allowed to recover from sedation and were returned to their cages.

\section{Administration of lavage solutions}

Five days after induction of colitis the animals were randomized to receive twice a day until day 8 colonic lavages containing 2 $\mathrm{ml}$ of one of three different fluids: saline (control group; $\mathrm{N}=10$ ), 10\% hypertonic glucose $(\mathrm{N}=10)$ and SCFA $(\mathrm{N}=10)$. The SCFA solution contained $60 \mathrm{mM}$ sodium propionate and $40 \mathrm{mM}$ sodium N'-butyrate (Sigma Chemical Co., St. Louis, MO, USA). Although acetate is the most abundant SCFA in the colon we deliberately excluded it from the mixture because acetic acid was used to promote the experimental colitis. The solution was adjusted to an osmolarity of 280-290 mOsm by the addition of $\mathrm{NaCl}$ and then to a $\mathrm{pH}$ of 7.0 with either concentrated $\mathrm{NaOH}$ or $\mathrm{HCl}$ as appropriate. The saline $(\mathrm{pH}=7)$ and glucose $(\mathrm{pH}=5.5)$ solutions had similar osmolarity (approximately 290 mOsm). Animals that died during the experi- 
ment were replaced with others.

\section{Macro- and microscopic evaluations and DNA assay}

The rats were weighed daily and killed by an overdose of ether on the 8th day after the induction of colitis. At autopsy, the segment of colon located between the ileocecal valve and the peritoneal reflexion was dissected and freed from the mesocolon. The entire large bowel was weighed after being flushed with cold saline to remove the contents. The specimen was then opened longitudinally and the mucosa inspected and graded using a macroscopic score (13) (Table 1). The pilot study cited above had shown that from day 5 until day 10 , specimens achieved grade 9 to 10 in this rat model of colitis. A small specimen of the bowel wall containing all the layers was collected from a point $2 \mathrm{~cm}$ above the peritoneal reflexion, fixed in $15 \%$ formalin solution and sent for histological examination. Histological sections cut sagitally to the serosa were stained with hematoxylin and eosin and studied by an observer blinded to the animal groups. Crypt depth (CD) and colonic wall width (WW) were measured (in $\mu \mathrm{m})$ on each slide using a micrometer. The mean value of the ten best-oriented crypts was considered to represent the data for each specimen. WW, measured at the same site as $\mathrm{CD}$, was defined as the distance from the serosa to the lumen. A score ranging from 1 to 4 was used to evaluate the intensity of the microscopic ulcerative process in the mucosa. In this system, $1=$ no ulceration; $2=$ minimal ulceration (less than one microscopic field at 100X magnification); 3 = large ulceration (ulcer larger than one microscopic field at 100X magnification), and $4=$ specimen without the mucosa (total ulceration). The rest of the mucosa of the colon was stripped out using a glass slide and assayed for DNA content (14).

A group of normal rats was also used for both histological (CD and WW values) and DNA studies.

\section{Statistical analysis}

One-way analysis of variance or the Kruskal-Wallis test was used to compare the data among groups depending on the characterization of the dependent variables and the homogeneity of the sample as assessed by Levene's test. When $\mathrm{P}<0.05$, differences among groups were identified by the Tukey test. The data are reported as mean $\pm \mathrm{SD}$ or median [range] as appropriate.

\section{Results}

One animal from the hypertonic glucose group died on the 6th day after induction of colitis. Autopsy showed fecal peritonitis due to colonic perforation. All animals lost weight from the beginning to the end of the study. There was no difference in weight between groups before (control: $350 \pm 35 \mathrm{~g}$; glucose: $332 \pm 47 \mathrm{~g}$, SCFA: $321 \pm 14 \mathrm{~g}, \mathrm{P}>0.05$ ) or after the experiment (control: $329 \pm 46 \mathrm{~g}$, glucose: $301 \pm 40 \mathrm{~g}$, SCFA: $311 \pm 29 \mathrm{~g}$, $\mathrm{P}>0.05$ ). However, the weight of the colon was significantly lower in the SCFA group $(3.8 \pm 0.5 \mathrm{~g})$ than in both the control $(5.3 \pm$ $2.1 \mathrm{~g})$ and glucose $(5.2 \pm 1.3 \mathrm{~g})$ groups $(\mathrm{P}<0.05)$.

The results of macroscopic evaluation of the colitic mucosa can be seen in Figure 1. The severity of inflammation was significantly lower in SCFA-treated rats (grade 2

\begin{tabular}{|c|c|}
\hline Score & Mucosa \\
\hline 0 & Normal \\
\hline 1 & Hyperemia \\
\hline 2 & Hyperemia and edema without ulceration \\
\hline 3 & Single and small ulceration $(<1 \mathrm{~cm})$ \\
\hline 4 & Two or more small ulcerations $(<1 \mathrm{~cm})$ \\
\hline 5 & Ulceration of more than $1 \mathrm{~cm}$ in length \\
\hline $6-10$ & $\begin{array}{l}\text { Injury of more than } 2 \mathrm{~cm} \text { in length, with } \\
\text { the score increased by } 1 \text { for each } \\
\text { additional centimeter of ulceration }\end{array}$ \\
\hline
\end{tabular}


Figure 1 - Median (range) of the macroscopic score for the three treatment groups. $* \mathrm{P}<0.01$ vs all other groups (Kruskal-Wallis test followed by Tukey test).
[1-5]) compared with both controls (grade 9 [4-10]) and glucose-treated (grade 9 [2-10]) animals.

There was no difference in the histologic morphometric values (CD and $\mathrm{WW}$ ) among the three groups of colitic animals. Compared to normal rats, both $\mathrm{CD}$ and $\mathrm{WW}$ were

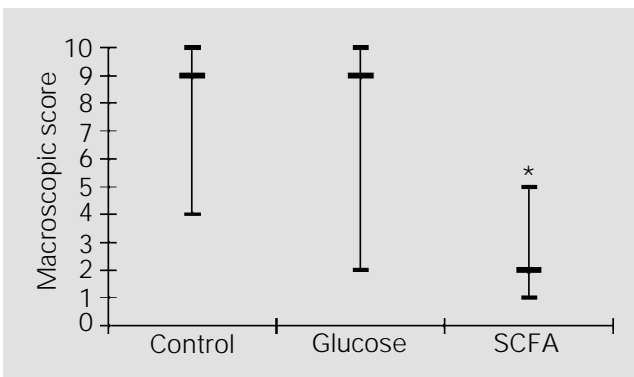

Figure 2 - Median (range) of crypt depth (A) and wall width (B) in the three treatment groups and in normal rats. $* \mathrm{P}<0.05$ vs all other groups. $* * P<0.01$ vs control and $\mathrm{P}<0.05$ vs glucose (Kruskal-Wallis test followed by Tukey test)
Figure 3 - Median (range) of DNA content in the three treatment groups and in normal rats. $* \mathrm{P}<0.05$ vs control and $\mathrm{P}<0.01$ vs glucose (Kruskal-Wallis test followed by Tukey test).
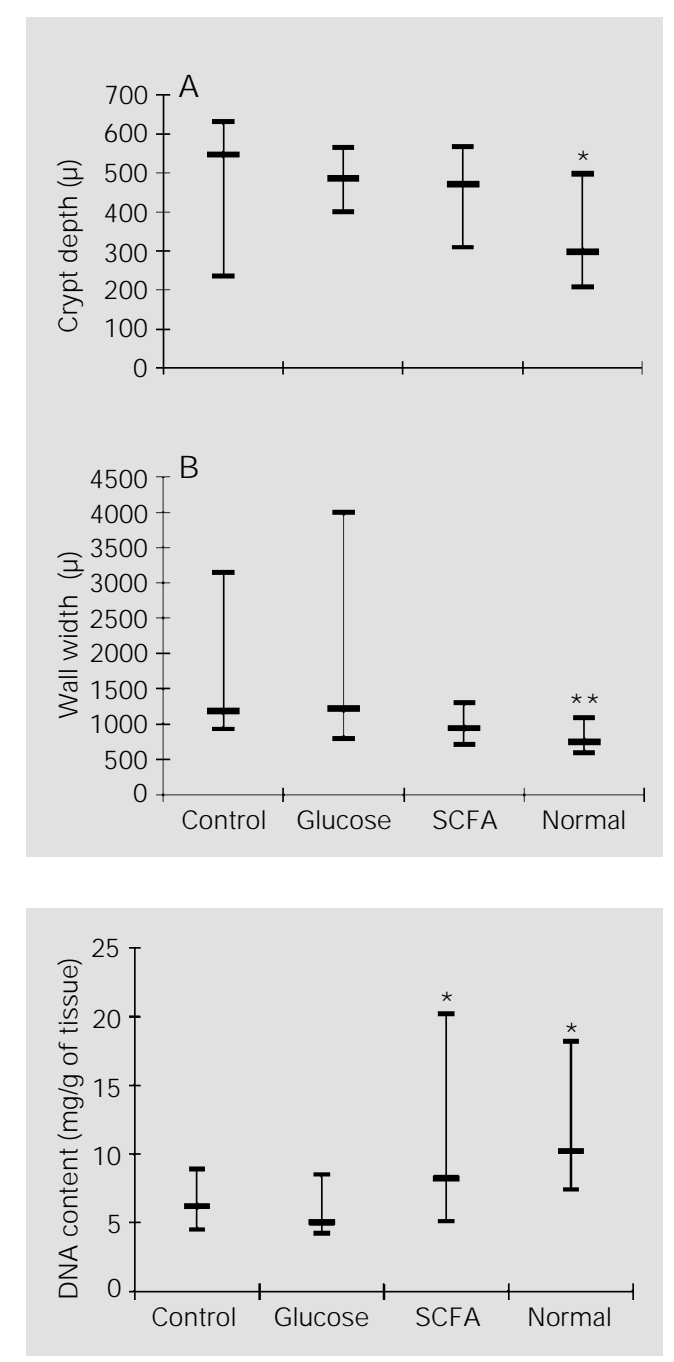

significantly higher in all three groups except for WW in the SCFA group which did not differ from the normal group (Figure 2). The ulceration score was significantly higher $(\mathrm{P}<0.05)$ in the glucose $(3[1-4])$ and control (3 [1-4]) groups than in the SCFA group $(1[1-3])$.

The DNA content of the colonic mucosa of both normal (10.2 [7.4-18.2] mg/g of tissue) and SCFA rats $(8.2$ [5.0-20.2] mg/g of tissue) was higher than in either of the other two groups (glucose: 5.1 [4.2-8.5] mg/g of tissue, $\mathrm{P}<0.01$ and controls: 6.2 [4.5-8.9] $\mathrm{mg} / \mathrm{g}$ of tissue, $\mathrm{P}<0.05$ ) (Figure 3 ).

\section{Discussion}

Acetic acid-induced colitis causes a relatively bland epithelial necrosis and edema that may extend into the lamina propria and submucosa (15). The nonspecific nature of the mucosal injury and the lack of chronicity are the most questionable factors of this model. However, the mucosal and submucosal inflammation that follows the initial epithelial injury is associated with activation of arachidonic acid pathways and is inhibited by leukotriene blockade, prostaglandin analogues, phospholipase A2 inhibitors and glucocorticoids (16). Moreover, the inflammation promoted by topically applied acetic acid is improved by the use of sulfasalazine and glucocorticoids. These similarities suggest some resemblance to human colitis, so that this may be considered a suitable model. Furthermore, the advantages of acetic acidinduced colitis are its low cost and easy administration (16).

The present results suggest that SCFA enhance the re-epithelialization of the colitic mucosa. Compared with both saline and hypertonic glucose, SCFA was the most effective agent in inducing recovery of the damaged mucosa. Not only were both the macroand microscopic parameters higher in SCFAtreated animals when compared with the other groups, but also the DNA content of 
the mucosa was higher in this group. Furthermore, the results observed in SCFA animals were closest to those observed in normal rats. Taken together, these findings suggest that a more rapid regeneration of the epithelium occurs when SCFA are employed.

A lack of luminal concentration of SCFA seems to occur in ulcerative colitis $(2,17)$. This scarcity is possibly due to a reduction of colonic anaerobic bacterial flora that may exist in both clinical and experimental colitis (18). Thus, we may speculate that an increased availability of these substrates may reinforce the nutrition of the colonocytes and reduce the inflammatory response of the colonic mucosa. Indeed, some reports have recently claimed that topical use of enemas containing SCFA improved the clinical condition and the endoscopic findings in patients with distal ulcerative colitis $(9,19)$.

The possible actions of SCFA on the colonic mucosa that may explain the good results obtained in this rat model are the well-documented property of these nutrients to promote colonic cell proliferation (3) and the stimulation of mucus release that may provide a more effective environment to protect the mucosa against bacterial invasion, diminish bacterial translocation and enhance the absorption of more SCFA by the colonocyte (20). Moreover, the SCFA, especially butyrate, may dilate arteries, thus increasing the blood flow to the large bowel mucosa and improving the mucosal uptake of oxygen (7). By also increasing the mucosal levels of transglutaminase, an enzyme responsible for the cross-linking of several proteins of the extracellular matrix and for the inhibition of fibrinolysis, butyrate may cause a faster re-epithelialization of the mucosa (11). Acetate seems to be less efficient for the colonic mucosa compared to butyrate and propionate $(3,5)$. Thus, criticisms for not including acetate in the composition of the SCFA solution used seem to be irrelevant.
Sugar has been used for centuries to accelerate wound healing (21) and may have some bacterial and bactericidal properties (22). In experimental colonic anastomosis, both SCFA and glucose may enhance perianastomotic mucosal proliferation (23) and intra-anastomotic resistance $(24,25)$. However, in this rat model of colitis, hypertonic glucose failed to promote regeneration and healing of the mucosa. This suggests an impaired utilization of glucose as a substrate by the bacterial metabolism to form SCFA. Possibly the acetic acid administered for the induction of colitis and the repeated hypertonic glucose enemas may have caused changes in the normal bacterial flora of the large bowel which may have impaired SCFA production from the available substrates. In the clinical setting, the intestinal bacterial flora seems to be modified in ulcerative colitis (18) and in experimental colitis there is a significant increase of aerobic Gram-negative bacilli within the colon (26). Thus, the production of SCFA by the bacterial metabolism could be impaired, though the colonocyte of both the colitic and normal mucosa is known to utilize SCFA (6).

The passage of bacteria and endotoxins from the intestinal lumen to the mesenteric lymph nodes, portal vein, liver and other extraintestinal sites may be increased in ulcerative colitis as a result of the disruption of the mucosal barrier and of the modified flora. In the rat model of bacterial translocation, the serum endotoxin concentration was positively correlated with the presence and extent of intestinal ulceration (26). Thus, by accelerating the regeneration of the colonic epithelium, SCFA may help to prevent the occurrence of bacterial translocation.

Although caution is necessary in extrapolating the findings of an experimental study to humans, the overall results support the hypothesis that SCFA may play an important role in the management of ulcerative colitis. However, hypertonic glucose is of no benefit. Since a reduction in the number of 
anaerobic bacteria is a common feature of active colitis regardless of its origin (18), the findings also suggest that the production of SCFA is impaired, though the colonocytes may utilize luminal SCFA if available.

\section{Acknowledgments}

We thank Dr. Robert T. Mathie, Department of Gastrointestinal Surgery, Division of Surgery, Anaesthetics and Intensive Care, Imperial College of Medicine, London, UK, for suggestions and assistance.

\section{References}

1. Kamm MA \& Senapati A (1992). Drug management of ulcerative colitis. British Medical J ournal, 305: 35-38.

2. Roediger WEW (1980). The colonic epithelium in ulcerative colitis: an energy deficiency disease. Lancet, 2: 712-715.

3. Roediger WEW \& Era DA (1982). Trophic effect of short chain fatty acids on mucosal handling of ions by the defunctioned colon. British J ournal of Surgery, 69: 2325.

4. Roediger WEW (1980). The role of anaerobic bacteria in the metabolic welfare of the colonic mucosa in man. Gut, 21: 793798.

5. Cummings JH (1981). Short chain fatty acids in the human colon. Gut, 22: 763779.

6. Clausen MR \& Mortensen PB (1995). Kinetic studies on colonocyte metabolism of short chain fatty acids and glucose in ulcerative colitis. Gut, 37: 684-689.

7. Mortensen FV, Nielsen H, Mulvany MJ \& Hessov I (1990). Short chain fatty acids dilate isolated human colonic resistance arteries. Gut, 31: 1391-1394.

8. Harig J M, Soergel KH, Komorowski RA \& Wood CM (1989). Treatment of diversion colitis with short-chain-fatty acid irigation. New England J ournal of Medicine, 320: 23-28.

9. Vernia P, Marcheggiano A, Caprilli R, Frieri G, Corrao G, Valpiani D, Di Paolo MC, Paoluzi P \& Torsoli A (1995). Short-chain fatty acid topical treatment in distal ulcerative colitis. Alimentary Pharmacology and Therapeutics, 9: 309-313.

10. D'Argenio G, Cosenza V, Delle Cave M, Iovino P, Delle Valle N, Lombardi G \& Mazzacca G (1996). Butyrate enema in experimental colitis and protection against large bowel cancer in a rat model. Gastroenterology, 110: 1727-1734.

11. D'Argenio G, Cosenza V, Sorrentini I, De Ritis F, Gatto A, Delle Cave M, D'Armiento FP \& M azzacca G (1994). Butyrate, mesalamine, and factor XIII in experimental colitis in the rat: effects on transglutaminase activity. Gastroenterology, 106: 399-404.

12. Butzner J D, Parmar R, Bell CJ \& Dalal V (1996). Butyrate enema therapy stimulates mucosal repair in experimental colitis in the rat. Gut, 38: 568-573.

13. Wallace J L, MacNaughton WK, Morris GP $\&$ Beck PL (1989). Inhibition of leukotriene synthesis markedly accelerates healing in a rat model of inflammatory bowel disease. Gastroenterology, 96: 29-36.

14. Gyles KW \& Myers A (1965). An improved diphenylamine method for estimation of desoxyribonucleic acid. Nature, 206: 9396.

15. Yamada $T$, Marshall $S$, Specian RD \& Grisham MB (1991). A comparative analysis of two models of colitis in rats. Gastroenterology, 102: 1524-1534.

16. Elson CO, Balfour Sartor R, Tennyson GS $\&$ Ridell RH (1995). Experimental models of inflammatory bowel disease. Gastroenterology, 109: 1344-1367.

17. Vernia P, Caprille R, Latella G, Barbetti F, Magliocca FM \& Cittadini M (1988). Fecal lactate and ulcerative colitis. Gastroenterology, 95: 1564-1568.

18. Fabia R, Ar'Rajab A, J ohansson $M L$, Andersson $\mathrm{R}$, Willén $\mathrm{R}$, J eppsson $\mathrm{B}$, Molin G \& Bengmark S (1993). Impairment of bacterial flora in human ulcerative colitis and experimental colitis in the rat. Digestion, 54: 248-255.
19. Senagore AJ , MacKeigan J M, Scheider M \& Ebrom J S (1992). Short-chain fatty acid enema: a cost-effective alternative in the treatment of nonspecific proctosigmoiditis. Diseases of the Colon and Rectum, 35: 923-927.

20. Roediger WEW (1990). The starved colon - Diminished mucosal nutrition, diminished absorption, and colitis. Diseases of the Colon and Rectum, 33: 858-862.

21. Forrest RD (1982). Sugar in the wound. Lancet, 1: 861

22. Rahal F, Mimica I, Pereira $V \&$ Athie $E$ (1983). O açúcar no tratamento local das infecções das feridas cirúrgicas. Revista do Colégio Brasileiro de Cirurgiões, 10: 135-136.

23. Aguilar-Nascimento J E, Oliveira-Neto J $P$, Mathie RT \& Williamson RCN (1997). Effect of intra-operative nutritional solutions on peri-anastomotic colonic mucosa in experimental large bowel obstruction. Digestive Diseases and Sciences, 42: 25812584.

24. Rolandelli RH, Koruda MJ, Settle RG \& Rombeau J L (1986). Effects of intraluminal infusion of short-chain fatty acids on the healing of colonic anastomosis in the rat. Surgery, 100: 198-203.

25. Aguilar-Nascimento J E, Mathie RT, Man W \& Williamson RCN (1995). Enhanced intra-anastomotic healing by operative lavage with nutrient solutions in experimental left-sided colonic obstruction. British J ournal of Surgery, 82: 461-464.

26. Gardiner KR, Erwin PJ , Anderson NH, Barr J G, Halliday MI \& Rowlands BJ (1993). Colonic bacteria and bacterial translocation in experimental colitis. British J ournal of Surgery, 80: 512-516. 